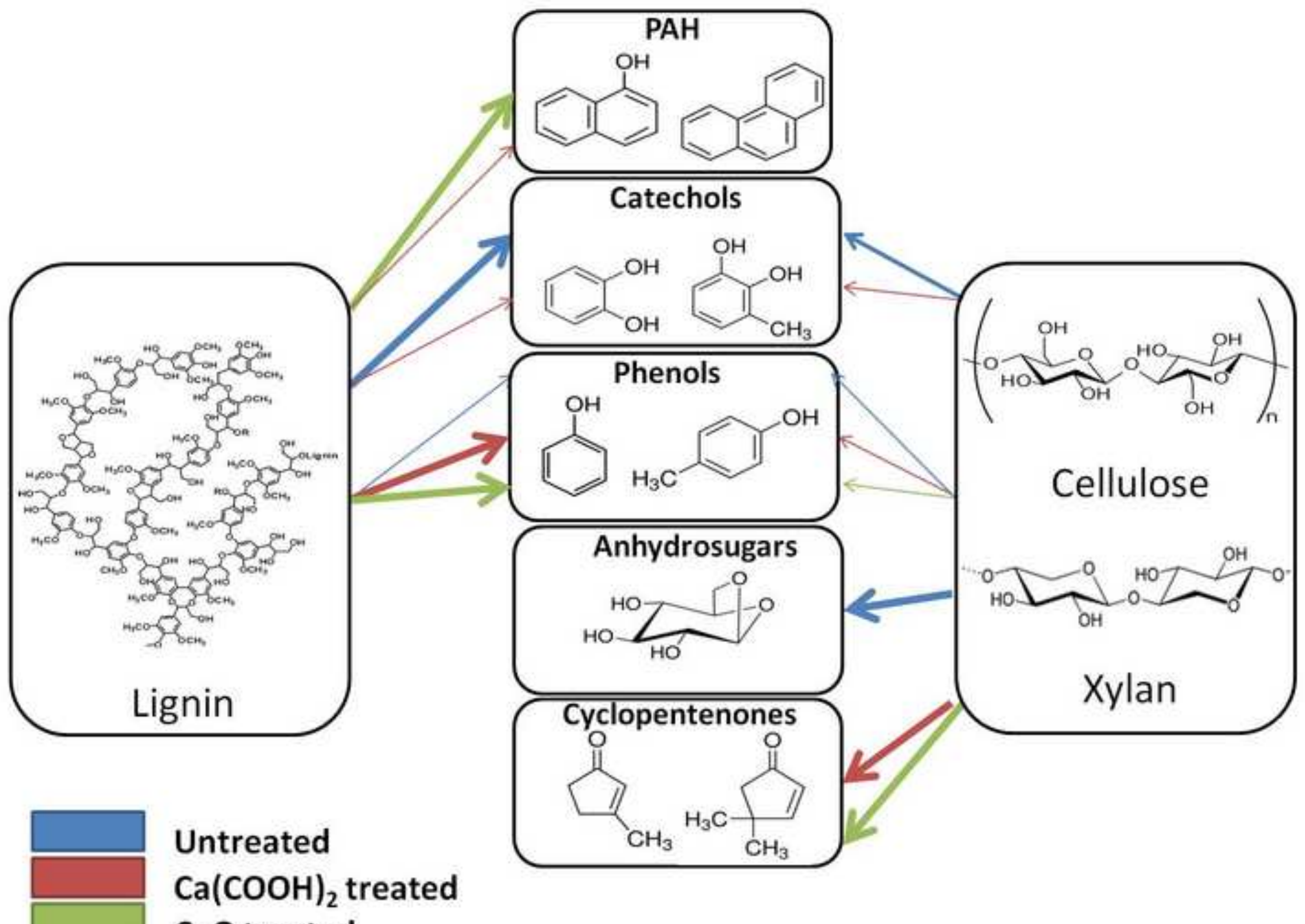

$\mathrm{CaO}$ treated 


\title{
Calcium-Catalyzed Pyrolysis of Lignocellulosic Biomass Components
}

\section{Paige A. Case ${ }^{\mathrm{a}}$, Chi Truong ${ }^{\mathrm{a}}$, M. Clayton Wheeler ${ }^{\mathrm{a}, \mathrm{b}}$ and William J. DeSisto ${ }^{\mathrm{a}, \mathrm{b} *}$}

a. Department of Chemical and Biological Engineering, University of Maine, Orono, ME 04469

b. Forest Bioproducts Research Institute, University of Maine, Orono, ME 04469

\begin{abstract}
The present study examines the effect of calcium pretreatment on pyrolysis of individual lignocellulosic compounds. Previous work has demonstrated that the incorporation of calcium compounds with the feedstock prior to pyrolysis has a significant effect on the oxygen content and stability of the resulting oil. The aim of this work was to further explore the chemistry of calcium-catalyzed pyrolysis. Bench-scale pyrolyis of biomass constituents, including lignin, cellulose and xylan is performed and compared to the oils produced from pyrolysis of the same components after calcium pretreatment. The resulting oils were analyzed by quantitative GC-MS and SEC. These analyses, together with data collected from previous work provide evidence which was used to develop proposed reaction pathways for pyrolysis of calcium-pretreatment biomass.

*Corresponding author
\end{abstract}




\section{Introduction}

For several decades, fast pyrolysis of lignocellulosic biomass has been a promising route to produce renewable fuels and chemicals because of the robustness of the process and the high liquid yields produced. Recently, however, it has become clear that there are significant issues with downstream processing of pyrolysis oil to produce a drop-in fuel. Pyrolysis oil is highly oxygenated, making it unstable during storage for any appreciable length of time. Upgrading processes to simultaneously hydrogenate and deoxygenate use moderately high temperatures which increase the rate of polymerization of the oil.

Because of this, a low-temperature stabilization step is required before hydrodeoxygenation can be performed (Mercader et al., 2011; Venderbosch et al., 2010). This creates a significant economic barrier to production of transportation fuels from pyrolysis. In order to overcome these issues, catalysts have been added directly to the pyrolysis reactor to directly produce oil with lower oxygen content (Agblevor et al., 2010; Carlson et al., 2009). Zeolite catalysts, specifically ZSM-5, are the typical choice for catalytic fast pyrolysis. This choice is based on the successful use of zeolites in the petroleum refining industry. While other types of catalysts have been studied (Di Blasi et al., 2008; Lu et al., 2009; Meesuk et al., 2011; Veses et al., 2014), zeolites are still used primarily.

The proposed mechanism for zeolite pyrolysis is an acid-catalyzed "carbon pool" chemistry, similar to that observed for catalytic conversion of methanol to olefins (Wang et al., 2003). In this mechanism, oxygenated biomass intermediates (mainly anhydrosugars) are fragmented and oxygen is removed in the form of $\mathrm{CO}, \mathrm{CO}_{2}$, and $\mathrm{H}_{2} \mathrm{O}$. The remaining hydrocarbon fragments, such as short-chain olefins, then combine to 
produce thermodynamically-favourable aromatics. In the hydrogen-deficient, oxygen-rich pyrolysis environment, however, this chemistry also promotes formation of carbonaceous residues ("coke") on the surface of the catalyst. This coke lowers the acidity of the catalyst surface resulting in deactivation (Du et al., 2013). The coke formed on the catalyst can be removed by combustion, and circulating fluidized bed reactors have been employed for continuous catalyst regeneration. This reactor design adds complexity to the pyrolysis system, increasing the capital and operating costs associated with the process.

In addition to catalyst coking, zeolite catalysts present other technical issues for biomass pyrolysis. The high temperatures for pyrolysis and regeneration, as well as the presence moisture from the biomass, can cause detrimental changes in the pore structure and surface composition of the zeolite (Vitolo et al., 2001). Also, perhaps most significantly, zeolite catalysts can be irreversibly fouled by alkali and alkaline earth metals present in biomass feedstocks. This fouling leads to loss of acidity and activity of the catalyst (Mullen \& Boateng, 2013; Paasikallio et al., 2014).

In order to avoid the issues associated with solid-acid catalysts, such as zeolites, research has focused on the application of basic catalysts for fast pyrolysis. By employing cations such as alkali and alkaline earth metals (AAEM), synergy between the catalyst and naturally occurring ash components in the biomass can be achieved. In this approach, inorganic compounds which are always present in biomass do not foul or deactivate the catalysts, allowing for potential simplification of reactor design and improved economics. Results have been reported previously on the effect of various calcium salts on the fast pyrolysis of pine, lignin, and tannins with a particular emphasis on calcium formate 
(Case et al., 2014a; Case et al., 2014b; Mukkamala et al., 2012). In this work, the effects of two calcium compounds, calcium oxide and calcium formate, are investigated for pyrolysis of lignin, cellulose and xylan. These two particular calcium compounds were chosen after studying several pretreatments because calcium formate showed particular action as a hydrogen donor and calcium oxide showed the most significant deoxygenation activity. The use of lignocellulosic model compounds in bench-scale pyrolysis experiments provides information about the origin of particular compounds observed during previous pyrolysis experiments and allows for elucidation of mechanistic pathways.

\section{Materials and Methods}

\subsection{Feedstock Preparation}

Lignocellulosic compounds used were Indulin AT (sodium-free kraft lignin, MeadWestVaco), spray-dried nanocellulose produced mechanically from kraft pulp (UMaine Process Development Center), and xylan from beechwood (TCI chemicals). The mass loading of calcium used was the same as in previous studies, $0.43 \mathrm{~g}$ calcium $/ \mathrm{g}$ biomass component (Case et al., 2014a; Case et al., 2014b). This loading corresponds to the addition of $140 \mathrm{~g}$ calcium formate and $60 \mathrm{~g}$ calcium oxide, respectively, to $100 \mathrm{~g}$ biomass component. In all cases, the mixture of biomass component/calcium compound was oven dried to $5-10 \%$ moisture and sieved to achieve particles smaller than $1.5 \mathrm{~mm}$.

\subsection{Pyrolysis}

The pretreated components were pyrolyzed with 40-60 mesh sand as heat transfer medium in a $3.5 \mathrm{~cm} \times 30 \mathrm{~cm}$ entrained flow reactor described in detail elsewhere 
(DeSisto et al., 2010). The reactor temperature was measured using two K-type thermocouples located on the vertical axis measured 3.0 and 9.5 in. from the top of the reactor. The pine/calcium formate mixture was metered through a screw feeder and pneumatically fed into the reactor, using a nitrogen flow rate of $6 \mathrm{~L} / \mathrm{min}$. Feed rates varied somewhat depending on the material properties, but the vapor residence time was held constant by the nitrogen flow. The pyrolysis temperature was $500{ }^{\circ} \mathrm{C}$ for all experiments. Immediately downstream of the reactor, char was separated using a hot gas filter (HGF) also held constant at $500{ }^{\circ} \mathrm{C}$. The total vapor residence time in the fluidized bed reactor and the HGF was 10-12 sec, with about $90 \%$ of that time in the HGF. After the vapor passed through the hot gas filter, the liquid was collected in a condenser operated at $6^{\circ} \mathrm{C}$, followed by an electrostatic precipitator (ESP) to collect aerosols.

\subsection{Product Characterization}

The organic phase of the bio-oil naturally phase-separated from water, however all analysis was conducted on oils collected from the electrostatic precipitator to ensure that there was no residual water.

\subsubsection{Size Exclusion Chromatography}

Size exclusion chromatography (SEC) was performed using an Shimadzu HPLC-GPC equipped with two columns measuring 1-1k Daltons and 1k-20k Daltons, respectively, with $\mathrm{N}, \mathrm{N}$-dimethylformamide (DMF)/Tricholoracetic acid/LiBr as the mobile phase. All of the oil samples were completely soluble in this solvent mixture, as well as the Indulin AT feedstock. The nanocellulose and xylan feedstocks were not soluble however, so no data for the molecular weight distributions of these feedstocks is presented. Due to the relatively low molecular weight of the oils produced with hot gas filtration, a large 
fraction of the sample elutes at the end of the calibration range with low resolution, making it difficult to quantitatively determine the molecular weight distribution and average molecular weight of an unknown sample. Therefore, results from this method were used for comparative purposes only.

\subsubsection{Quantitative Analysis by GC/MS}

Chemical composition was characterized using a Shimadzu Q2010 gas chromatographmass spectrometer (GC-MS). The samples were diluted with ethyl acetate and prepared by adding known amounts of butylated hydroxytoluene as a recovery standard and biphenyl as an internal standard. All of the samples were derivatized with N-Methyl-N(trimethylsilyl) trifluoroacetamide (MSTFA) for one hour before analysis. Compounds reported were verified by both mass spectral fragmentation pattern and retention time matches to genuine standards.

\section{$3 \quad$ Results and Discussion}

\subsection{Gas Chromatography-Mass Spectrometry (GC-MS)}

The organic fractions of the oil products were analyzed by GC-MS. While this technique provides valuable information about the chemical structure of oil components, it can identify only a small fraction of the pyrolysis oil (typically less than 20\%). This is because of several factors. First, because of the diversity of compounds present in pyrolysis oils, choosing a column which is suitable for all compounds is impossible. For example, oxygenated compounds do not elute well on columns with non-polar phases. This issue can be partially mitigated by using trimethylsilyl (TMS) derivitization to increase the number of detectable compounds by decreasing the polarity of hydroxylated 
compounds. When derivitization is employed, however there can be co-elution of many low-molecular-weight acids and aldehydes with the solvent and MSTFA decomposition product peaks. Another limitation of GC/MS analysis for characterization of pyrolysis oils is the amount of high molecular weight compounds like polyaromatic hydrocarbons (PAH) and long-chain fatty acids present in the oil. These compounds are generally not volatile enough to be desorbed from the GC column. Finally, although many peaks can be examined qualitatively, there are practical and economic limitations to quantitative identification of all peaks present in GC/MS spectra. Because of this, only the most significant peaks are quantified using genuine standards.

\subsubsection{Lignin}

Table 1 presents the major chemical compounds present in the oil produced from pyrolysis of Indulin AT lignin. This data shows that without pretreatment, dihydroxybenzenes are the major product, including both unsubstituted and alkyl substituted catechol. This is congruent with previous results where hot gas filtration was employed. (Case et al., 2014c; Mukkamala et al., 2012) When calcium formate was used as a pretreatment, the concentration of catechols was dramatically reduced and there was an increase in the amount of alkylated phenols produced. With calcium oxide pretreatment, catechols completely disappeared and the concentration of both alkylated phenols and polyaromatic hydrocarbons (PAH) was increased. These results are consistent with previous work (Case, et al. 2014b) and confirm that calcium compounds catalyze deoxygenation in the form of dehydroxylation. Another observation that can be made from the GC/MS analysis of lignin oils is that m-cresol was selectively formed with calcium pretreatment. Figure 1 shows the percent change in the concentration of the three 
cresol isomers with calcium formate and calcium oxide pretreatment relative to the concentration of the isomers in the oil derived from untreated lignin. The monomeric structure of lignin has no substituent on the meta- position, indicating that mechanism for calcium-catalyzed pyrolysis of lignin-type structures promotes alkylation at the meta position relative to the hydroxyl substituent. Additionally, PAH were formed only when lignin was pretreated with calcium oxide, not with calcium formate. This provides further insight into potential mechanistic pathways, supporting the hypothesis that calcium formate is an active hydrogen donor. Retene was the only PAH formed with calcium formate pretreatment. As discussed in previous work, retene is the calcium-catalyzed decomposition product of abietic acid, one of the most abundant resin acids present in pine (Case et al., 2014b). It is not surprising that it was also present in the calciumcatalyzed pyrolysis of Indulin AT as well, since pine is used as the starting material for its production and resin acids often end up in the black liquor during the kraft pulping process.

\subsubsection{Cellulose}

Analysis of the oils produced from pyrolysis of nanocellulose is presented in Table 2. An interesting initial observation is that a portion of the untreated cellulose formed catechols under these pyrolysis conditions. While a much lower concentration $(11.2 \mathrm{mg}$ catechol/g oil for cellulose vs. $69.5 \mathrm{mg}$ catechol/g oil for lignin), this indicated that the carbohydrate fraction of biomass does contribute to the phenolics present in the pyrolysis oil derived from whole biomass. With calcium pretreatment, the same conversion of catechols to phenols was observed for cellulose. This may provide evidence that calcium-catalyzed 
dehydroxylation is a secondary or tertiary pyrolysis reaction with catechol as the intermediate.

Another phenomenon observed from the data is the disappearance of anhydrosugars such as levoglucosan with calcium pretreatment. Pyrolysis of untreated cellulose produced levoglucosan, the expected product from thermal degradation of cellulose. When calcium pretreatment was employed, alkyl-substituted cyclopentenones were produced. These compounds have been reported in previous studies on the affect of alkali compounds on biomass pyrolysis, (Di Blasi et al., 2009) as well as for pyrolysis of calcium levulinate (Schwartz et al., 2010). Other literature shows that alkali and alkaline earth metals promote gas forming reactions over depolymerization and dehydration (Patwardhan et al., 2010), but does not discuss formation of phenolics and cyclic ketones. This difference could be due to several factors; first, the experiments performed by the authors used a micropyrolyzer with very small cellulose particle sizes $(50 \mu \mathrm{m})$. The heatand mass-transfer rates as well as the residence times are very different than those in a fluidized bed with $1.5 \mathrm{~mm}$ particles. Second, the authors studied microcrystalline cellulose, which likely behaves differently than the nanocellulose used in this study, which has both crystalline and amorphous regions. Finally, the authors were using much lower mass loadings of calcium, which will undoubtedly affect the pyrolysis chemistry.

\subsubsection{Xylan}

Analysis of products obtained from pyrolysis of xylan, given in Table 3, showed many similarities to cellulose. Again, a fraction of the untreated xylan oil consisted of catechols, which disappeared with calcium pretreatment. There was no clear trend observed for phenols, but like cellulose, calcium pretreatment promotes the formation of 
alkylated cyclopentenones from xylan. The relative production of these cyclopentenones between the three components, with and without pretreatment is illustrated in Figure 2.

\subsection{Size Exclusion Chromatography (SEC)}

Because only a relatively small fraction of the oil can be characterized using GC/MS, SEC was used to examine the molecular weight distribution of the whole oil. The results of this analysis are presented in Figures 3-5. Figure 3 compares the molecular weight distribution for untreated and calcium pretreated pyrolysis oils derived from lignin. This analysis shows that calcium pretreatment shifted the molecular weight distribution of the whole oil towards lower molecular weights; calcium oxide pretreatment had a more dramatic effect than calcium formate.

Analysis of the untreated cellulose oil (Figure 4) shows a sharp peak at approximately 22.5 minutes. This elution time corresponds to the molecular weight of cellobiose, the dimer of D-glucose, which is not detectable in GC analysis. This may indicate that the cellulose polymer was not completely degraded at the pyrolysis conditions of this study. The pretreated oils, however, showed a distribution shifted towards lower molecular weight, which likely corresponds with the alkylated cyclopentenones observed in GC/MS analysis.

Comparison of the SEC analysis of oils produced from xylan does not show such a dramatic shift in molecular weight distribution as lignin or cellulose. This likely has more to do with the fact that the xylan starting material has a much lower degree of polymerization than either of the other two feedstocks, and less to do with a difference in mechanistic behavior. Figure 5 shows that while the untreated xylan oil is shifted towards lower molecular weight when compared to untreated lignin and cellulose oils, there was 
still a significant difference when this oil is compared to xylan-derived oils produced with calcium pretreatment.

\subsection{Proposed Reaction Pathways}

The use of individual lignocellulosic components provides further mechanistic insight compared with pyrolysis of pine. For example, when whole pine is pyrolyzed, the difference in formation of PAH between untreated biomass and pretreatment of calcium formate or oxide is not as clear, due to the presence of other PAH sources (resins, waxes). Also, the selective formation of m-substituted phenols from lignin is not as apparent when combined with the phenols produced from the carbohydrate fraction of the biomass. Observations from these experiments, as well as previous work found in literature provide evidence for potential reaction mechanisms.

The most significant transformation observed from the pretreatment of lignin is the dehydroxylation of catechol-type compounds, forming phenol-type compounds. This conversion occurs with both calcium formate and calcium oxide, but is more complete with the oxide pretreatment. This observation, together with previous results, indicates that the catalytic activity is affected by the basicity of the pretreatment compound (Case et al. 2014b). Figure 1 shows that m-substituted phenols were selectively produced from lignin with calcium pretreatment, which provides information about the particular mechanistic pathway which could be occurring. Softwood lignin is mainly composed of guaiacyl-type structures with para-substituents/linkages. The presence of metasubstituted phenols, therefore, is most likely due to a free radical mechanism. Also, the decrease in catechols is correlated not only with an increase in phenols in general, but also specifically with meta-cresol and other meta-substituted di- and tri-methylated 
phenols. These observations lead to the formulation of a proposed mechanism for the pyrolysis of lignin under these reaction conditions which is base-catalyzed and involves free-radical addition. In catechol, for example, the base abstracts a proton ortho to a hydroxyl leaving group resulting in the formation of a benzyne intermediate. This benzyne intermediate is unstable and subject to free-radical addition in the metaposition. This mechanism could occur with free hydroxyl groups, however is more likely to occur if the hydroxyl groups are associated with a calcium ion (chelated). In that case, there would be no competition for abstraction of the benzyl hydrogen atom with the more acidic hydrogen associated with the hydroxyl group. This type of mechanism would promote addition at the meta- position due to the hindrance of the ortho-position by the hydroxyl group. This particular mechanism is based on a catechol reactant because catechol intermediates are also observed from pyrolysis of the carbohydrate fractions. An additional fate for the benzyne intermediate could be the formation of PAHs through Diels-Alder condensation and dehydration with a reactant such as butadiene.

Both carbohydrates studied, cellulose and xylan, showed similar behavior with pretreatment. Cellulose is composed of $\beta-1,4$ linked D-glucose units, while xylan consists of $\beta$-D-xylose. The monomeric units have almost identical structure, with the glucose having a $\mathrm{CH}_{2}-\mathrm{OH}$ substituent on the $\mathrm{C}-5$ position. Based on these similarities, it is not surprising that they undergo similar reaction pathways. Literature has shown that calcium compounds promote decomposition of cellulose and glucose into D-isosaccharinic acid (Machell \& Richards, 1960; VanLoon \& Glaus, 1997). It is possible that under pyrolysis conditions, this acid (or calcium salt of the acid) may undergo cyclization and dehydration, producing a thermodynamically favorable cyclic ketone (such as methyl 
cyclopentenone). This hypothesis is also supported by the similarity of the products to those obtained during TDO of levulinic acid. Dehydration of the sugar intermediate results in formation of double bonds, which can then undergo free radical addition reactions, leading to formation of dimethyl- and trimethyl-cyclopentenones. The first step in this proposed pathway is slow degradation of the polysaccharide into the glucosaccharinic acid intermediate, and then fast cyclization and dehydration occurring at elevated pyrolysis temperatures.

These pathways are proposed based on analytical results and observations from studies exploring several aspects of pretreatment, including reactor conditions, feedstock type and pretreatment compound properties. They have not been experimentally proven, largely due to the difficulty associated with mechanistic confirmation in the harsh pyrolysis environment. At the elevated temperatures associated with pyrolysis, there is enough energy to overcome the activation barrier associated with almost any organic reaction. Additionally, the interaction between the gas phase and the solid phase adds another level of complexity to the problem. Because of these factors, many potential mechanisms can be proposed; those presented here only represent two which are plausible based on experimental evidence.

\section{Conclusions}

Calcium pretreated pyrolysis has the potential to produce bio-oil of similar quality and yield as catalytic fast pyrolysis with zeolites, using a more robust and cheaper catalyst. In order to further evaluate the potential of this process, however, fundamental knowledge about reaction kinetics and mechanisms must be developed. In this work, quantitative chemical analysis was used to characterize oil 
derived from pyrolysis of untreated and calcium-pretreated model components of biomass. This information provides experimental evidence which is used to develop potential mechanistic pathways.

\section{Acknowledgements}

The authors would like to acknowledge Elizabeth Stemmler, Brian Frederick and Raymond Fort for their valuable contributions. Also, the authors would like to thank Nathan Hill and Brett Barclay for their technical assistance. This work was supported by the U.S. Department of Energy, Office of Science, Basic Energy Sciences, under award \#DE-FG02-07ER46373 and the U.S. Department of Transportation, under award \#DTRT13-G-UTC43. 


\section{References}

1. Agblevor, F.A., Beis, S., Mante, O., Abdoulmoumine, N. 2010. Fractional catalytic pyrolysis of hybrid poplar wood. Industrial \& Engineering Chemistry Research, 49, 3533-3538.

2. Carlson, T., Tompsett, G., Conner, W., Huber, G. 2009. Aromatic Production from Catalytic Fast Pyrolysis of Biomass-Derived Feedstocks. Topics in Catalysis, 52(3), 241-252.

3. Case, P.A., Bizama, C., Segura, C., Clayton Wheeler, M., Berg, A., DeSisto, W.J. 2014a. Pyrolysis of pre-treated tannins obtained from radiata pine bark. Journal of Analytical and Applied Pyrolysis, 107(0), 250-255.

4. Case, P.A., Clayton Wheeler, M., DeSisto, W.J. 2014b. Formate Assisted Pyrolysis of Pine Sawdust for in-situ Oxygen Removal and Stabilization of Bio-oil. Bioresource Technology. 173, 177-184

5. Case, P.A., Wheeler, M.C., DeSisto, W.J. 2014c. Effect of Residence Time and Hot Gas Filtration on the Physical and Chemical Properties of Pyrolysis Oil. Energy \& Fuels. 28 (6), 3964-3969.

6. DeSisto, W.J., Hill, N., Beis, S.H., Mukkamala, S., Joseph, J., Baker, C., Ong, T.H., Stemmler, E.A., Wheeler, M.C., Frederick, B.G., van Heiningen, A. 2010. Fast 
Pyrolysis of Pine Sawdust in a Fluidized-Bed Reactor. Energy \& Fuels, 24, 26422651.

7. Di Blasi, C., Branca, C., Galgano, A. 2008. Products and global weight loss rates of wood decomposition catalyzed by zinc chloride. Energy \& Fuels, 22(1), 663-670.

8. Di Blasi, C., Galgano, A., Branca, C. 2009. Influences of the Chemical State of Alkaline Compounds and the Nature of Alkali Metal on Wood Pyrolysis. Industrial \& Engineering Chemistry Research, 48(7), 3359-3369.

9. Du, S.C., Valla, J.A., Bollas, G.M. 2013. Characteristics and origin of char and coke from fast and slow, catalytic and thermal pyrolysis of biomass and relevant model compounds. Green Chemistry, 15(11), 3214-3229.

10. Lu, Q., Xiong, W.M., Li, W.Z., Guo, Q.X., Zhu, X.F. 2009. Catalytic pyrolysis of cellulose with sulfated metal oxides: A promising method for obtaining high yield of light furan compounds. Bioresource Technology, 100(20), 4871-4876.

11. Machell, G., Richards, G.N. 1960. 384. Mechanism of saccharinic acid formation. Part I. Competing reactions in the alkaline degradation of 4-O-methyl-D-glucose, maltose, amylose, and cellulose. Journal of the Chemical Society (Resumed)(0), 1924-1931.

12. Meesuk, S., Cao, J.P., Sato, K., Ogawa, Y., Takarada, T. 2011. Study of Catalytic Hydropyrolysis of Rice Husk under Nickel-Loaded Brown Coal Char. Energy \& Fuels, 25(11), 5438-5443.

13. Mercader, F.D., Koehorst, P.J.J., Heeres, H.J., Kersten, S.R.A., Hogendoorn, J.A. 2011. Competition Between Hydrotreating and Polymerization Reactions During Pyrolysis Oil Hydrodeoxygenation. Aiche Journal, 57(11), 3160-3170. 
14. Mukkamala, S., Wheeler, M.C., van Heiningen, A.R.P., DeSisto, W.J. 2012. FormateAssisted Fast Pyrolysis of Lignin. Energy \& Fuels, 26(2), 1380-1384.

15. Mullen, C.A., Boateng, A.A. 2013. Accumulation of Inorganic Impurities on HZSM5 Zeolites during Catalytic Fast Pyrolysis of Switchgrass. Industrial \& Engineering Chemistry Research, 52(48), 17156-17161.

16. Paasikallio, V., Lindfors, C., Kuoppala, E., Solantausta, Y., Oasmaa, A., Lehto, J., Lehtonen, J. 2014. Product quality and catalyst deactivation in a four day catalytic fast pyrolysis production run. Green Chemistry, 16(7), 3549-3559.

17. Patwardhan, P.R., Satrio, J.A., Brown, R.C., Shanks, B.H. 2010. Influence of inorganic salts on the primary pyrolysis products of cellulose. Bioresource Technology, 101(12), 4646-4655.

18. Schwartz, T.J., van Heiningen, A.R.P., Wheeler, M.C. 2010. Energy densification of levulinic acid by thermal deoxygenation. Green Chemistry, 12(8), 1353-1356.

19. VanLoon, L.R., Glaus, M.A. 1997. Review of the kinetics of alkaline degradation of cellulose in view of its relevance for safety assessment of radioactive waste repositories. Journal of Environmental Polymer Degradation, 5(2), 97-109.

20. Venderbosch, R.H., Ardiyanti, A.R., Wildschut, J., Oasmaa, A., Heeres, H.J. 2010. Stabilization of biomass-derived pyrolysis oils. Journal of Chemical Technology and Biotechnology, 85(5), 674-686.

21. Veses, A., Aznar, M., Martinez, I., Martinez, J.D., Lopez, J.M., Navarro, M.V., Callen, M.S., Murillo, R., Garcia, T. 2014. Catalytic pyrolysis of wood biomass in an auger reactor using calcium-based catalysts. Bioresource Technology, 162, 250-258. 
22. Vitolo, S., Bresci, B., Seggiani, M., Gallo, M.G. 2001. Catalytic upgrading of pyrolytic oils over HZSM-5 zeolite: behaviour of the catalyst when used in repeated upgrading-regenerating cycles. Fuel, 80(1), 17-26.

23. Wang, W., Buchholz, A., Seiler, M., Hunger, M. 2003. Evidence for an initiation of the methanol-to-olefin process by reactive surface methoxy groups on acidic zeolite catalysts. Journal of the American Chemical Society, 125(49), 1526015267. 


\section{Figure Captions}

Figure 1. Relative change in concentration of the isomers of cresol with calcium formate and calcium oxide pretreatment of lignin feedstock

Figure 2. Concentration of alkylated cyclopentenones for each model biomass component with and without calcium pretreatment

Figure 3. Comparison of the molecular weight distribution of lignin feed, untreated and pretreated pyrolysis oils obtained from SEC analysis

Figures 4. Comparison of the molecular weight distribution of untreated and pretreated cellulose-derived pyrolysis oils obtained from SEC analysis

Figure 5. Comparison of the molecular weight distribution of untreated and pretreated xylan-derived pyrolysis oils obtained from SEC analysis 
Table 1. Major components present in pyrolysis oils derived from untreated and calciumpretreated Indulin AT lignin.

\section{Concentration (mg/g oil)}

\begin{tabular}{|c|c|c|c|}
\hline & Lignin & $\begin{array}{c}\text { Lignin + } \\
\mathrm{Ca}(\mathrm{COOH}) 2\end{array}$ & $\begin{array}{c}\text { Lignin + } \\
\mathrm{CaO}\end{array}$ \\
\hline 2-methyl-2-cyclopenten-1-one & - & 2.3 & - \\
\hline 2,3-dimethyl-2-cyclopenten-1-one & - & - & 9.3 \\
\hline Phenol & 24.5 & 27.2 & 12.9 \\
\hline o-cresol & 7.4 & 11.5 & 5.9 \\
\hline m-cresol & 5.9 & 16.8 & 18.1 \\
\hline p-cresol & 14.0 & 18.0 & 16.6 \\
\hline 2,5-dimethyl phenol & - & 4.3 & 5.6 \\
\hline 2,4-dimethyl phenol & 3.5 & 8.9 & 7.7 \\
\hline 3,5-dimethyl phenol & - & 2.9 & 9.4 \\
\hline 3,4-dimethyl phenol & - & 1.7 & 6.3 \\
\hline 4-ethyl phenol & 5.4 & 10.0 & 15.2 \\
\hline 4-vinyl phenol & 15.4 & 7.8 & 4.4 \\
\hline 2-methyl-4-ethyl phenol & - & 4.3 & 9.2 \\
\hline 2-methyl-4-vinyl phenol & 3.1 & 2.0 & - \\
\hline Catechol & 69.5 & 16.1 & - \\
\hline 4-methyl catechol & 16.0 & 5.5 & - \\
\hline 3-methyl catechol & 4.6 & 4.1 & - \\
\hline 4-ethyl catechol & 7.7 & 3.3 & - \\
\hline 1-Napthenol & 5.1 & 5.2 & 14.5 \\
\hline 2-Napthenol & 7.9 & 9.5 & 33.4 \\
\hline Methyl phenanthrenes & - & - & 14.5 \\
\hline Dimethyl phenanthrene & - & - & 23.8 \\
\hline Trimethyl phenanthrene & - & - & 6.5 \\
\hline Methyl vinyl phenanthrene & - & - & 4.7 \\
\hline Methyl ethyl phenanthrene & - & - & 15.0 \\
\hline Percent of oil identified & $19.0 \%$ & $16.1 \%$ & $23.3 \%$ \\
\hline
\end{tabular}


Table 2. Major components present in pyrolysis oils derived from untreated and calciumpretreated nanocellulose

Concentration (mg/g oil)

\begin{tabular}{|c|c|c|c|}
\hline & Cellulose & $\begin{array}{c}\text { Cellulose + } \\
\mathrm{Ca}(\mathrm{COOH}) 2\end{array}$ & $\begin{array}{c}\text { Cellulose + } \\
\mathrm{CaO}\end{array}$ \\
\hline 2-methyl-2-cyclopenten-1-one & - & 10.3 & 2.4 \\
\hline 3-methyl-2-cyclopentenone & - & 4.6 & 5.3 \\
\hline Dimethyl cyclopentenones & - & 21.3 & 12.4 \\
\hline Ethyl cyclopentenone & - & - & 2.7 \\
\hline Trimethyl cyclopentenones & - & 11.6 & 5.9 \\
\hline Ethylene glycol & 1.7 & - & - \\
\hline Phenol & 14.4 & 8.7 & 10.9 \\
\hline o-cresol & 5.8 & 7.4 & 8.7 \\
\hline m-cresol & 8.9 & 6.7 & 8.3 \\
\hline p-cresol & 1.8 & 2.0 & 3.7 \\
\hline 2,5-dimethyl phenol & - & 3.4 & 3.1 \\
\hline 2,4-dimethyl phenol & - & 4.2 & 5.1 \\
\hline 3,5-dimethyl phenol & - & 1.7 & 1.2 \\
\hline 2,6-xylenol & - & 2.6 & 0.9 \\
\hline 4-ethyl phenol & - & 2.0 & 2.4 \\
\hline 3,4-dimethyl phenol & - & 1.2 & 1.4 \\
\hline 2-methyl-3-ethyl phenol & - & 3.5 & 2.0 \\
\hline Catechol & 11.2 & - & - \\
\hline 4-methyl catechol & 3.6 & - & - \\
\hline 3-methylcatechol & 4.9 & - & - \\
\hline 1,4-dihydroxy benzene & 8.0 & 1.3 & 1.5 \\
\hline 4-ethyl catechol & - & 2.0 & 2.6 \\
\hline Levoglucosan & 15.9 & - & - \\
\hline Percent of oil identified & $7.6 \%$ & $9.5 \%$ & $8.5 \%$ \\
\hline
\end{tabular}


Table 3. Major components present in pyrolysis oils derived from untreated and calciumpretreated xylan

\begin{tabular}{|c|c|c|c|}
\hline & \multicolumn{3}{|c|}{ Concentration (mg/g oil) } \\
\hline & Xylan & $\begin{array}{c}\text { Xylan }+ \\
\mathrm{Ca}(\mathrm{COOH}) 2\end{array}$ & Xylan $+\mathrm{CaO}$ \\
\hline 2-methyl-2-cyclopenten-1-one & 3.3 & 4.7 & 2.7 \\
\hline 3-methyl-2-cyclopenten-1-one & 2.1 & 3.2 & 4.6 \\
\hline 2,3-Dimethyl-2-cyclopentenone & 5.9 & 10.8 & 16.9 \\
\hline Ethyl cyclopentenone & - & - & 2.4 \\
\hline Trimethyl cyclopentenone & - & 8.4 & 8.8 \\
\hline Ethylene glycol & 0.3 & - & - \\
\hline Phenol & 17.9 & 14.0 & 19.8 \\
\hline o-cresol & 14.0 & 12.9 & 17.3 \\
\hline m-cresol & 13.8 & 9.5 & 13.2 \\
\hline p-cresol & 5.3 & 4.1 & 5.0 \\
\hline 2,5-dimethyl phenol & 4.1 & 4.0 & 3.9 \\
\hline 2,4-dimethyl phenol & 3.5 & 5.9 & 5.7 \\
\hline 3,5-dimethyl phenol & 2.5 & - & 1.2 \\
\hline 3,4-dimethyl phenol & 1.6 & - & 1.4 \\
\hline 4-ethyl phenol & 1.2 & - & - \\
\hline 3-ethyl phenol? & 2.8 & - & 3.6 \\
\hline vinyl phenol & 2.9 & - & - \\
\hline methyl-ethyl phenol & 3.0 & 2.7 & 2.6 \\
\hline Catechol & 4.3 & - & - \\
\hline 4-methyl catechol & 1.3 & - & - \\
\hline 3-methylcatechol & 5.0 & - & - \\
\hline 1,4-dihydroxy benzene & 4.1 & 2.1 & 1.0 \\
\hline 4-ethyl catechol & 5.8 & 3.4 & 1.9 \\
\hline 1-Napthenol & 7.2 & - & 3.1 \\
\hline 2-Napthenol & 11.2 & - & 2.7 \\
\hline Percent of oil identified & $12.3 \%$ & $8.6 \%$ & $11.8 \%$ \\
\hline
\end{tabular}


Figure 1.

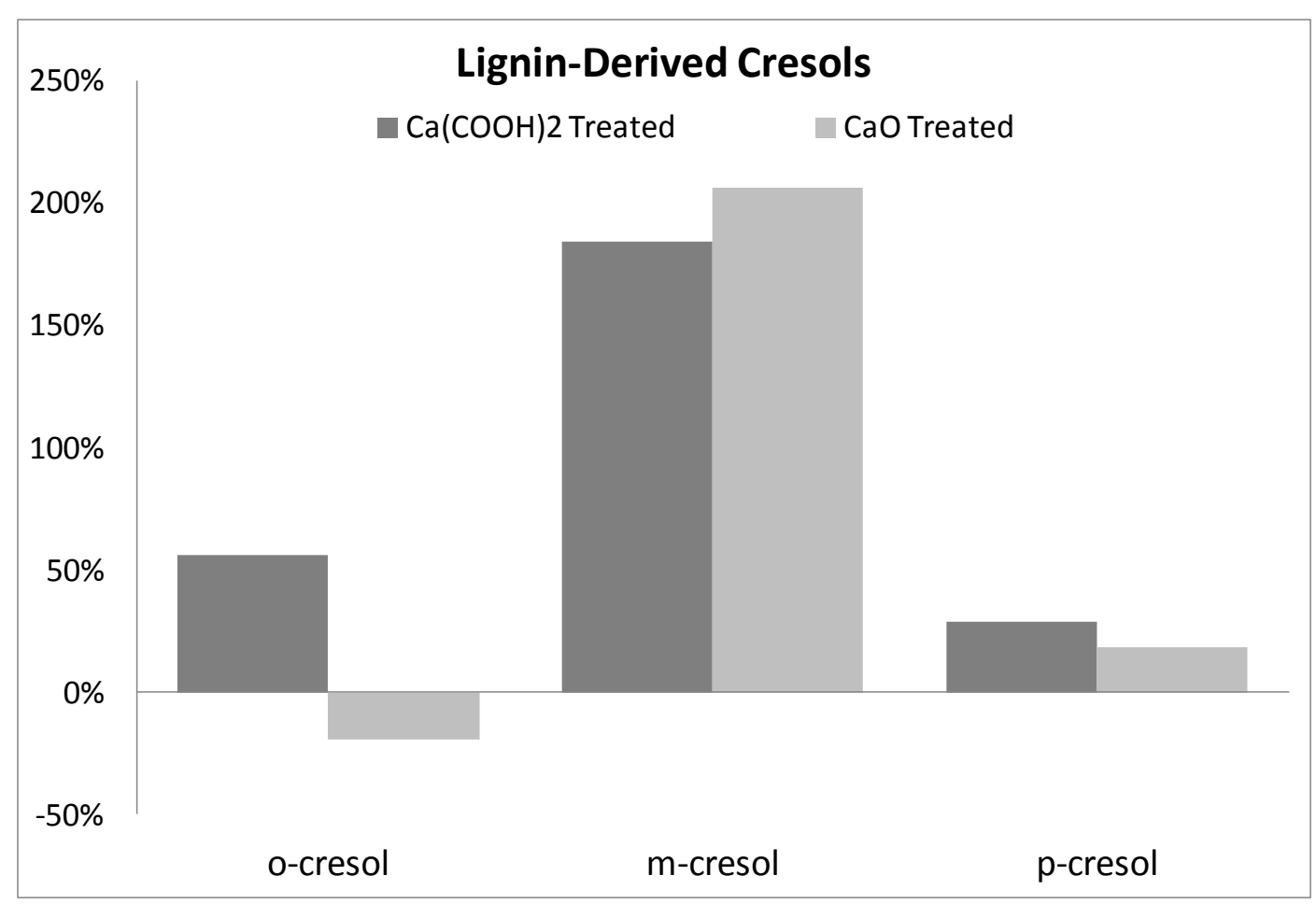

Figure 2.

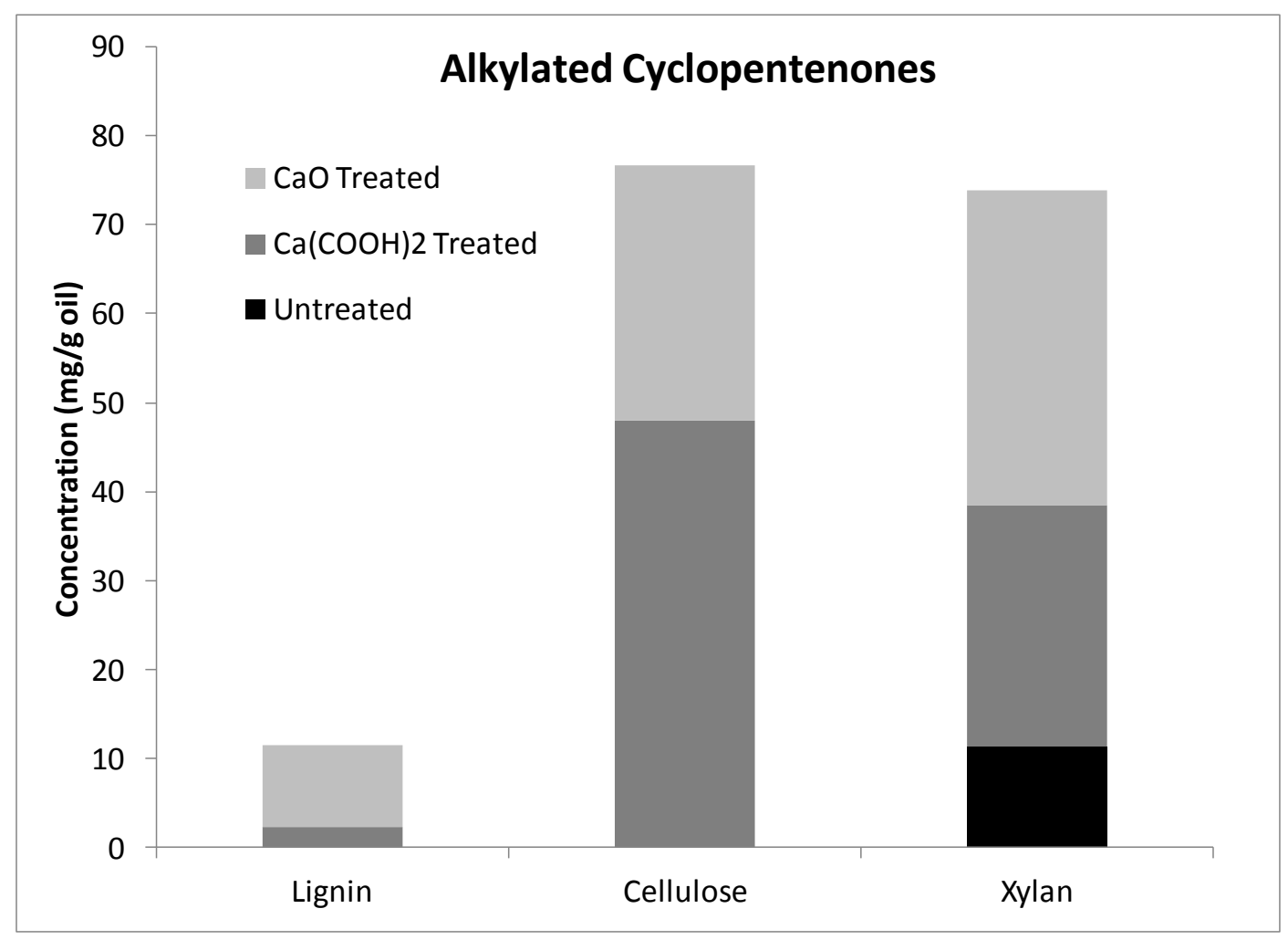


Figure 3.

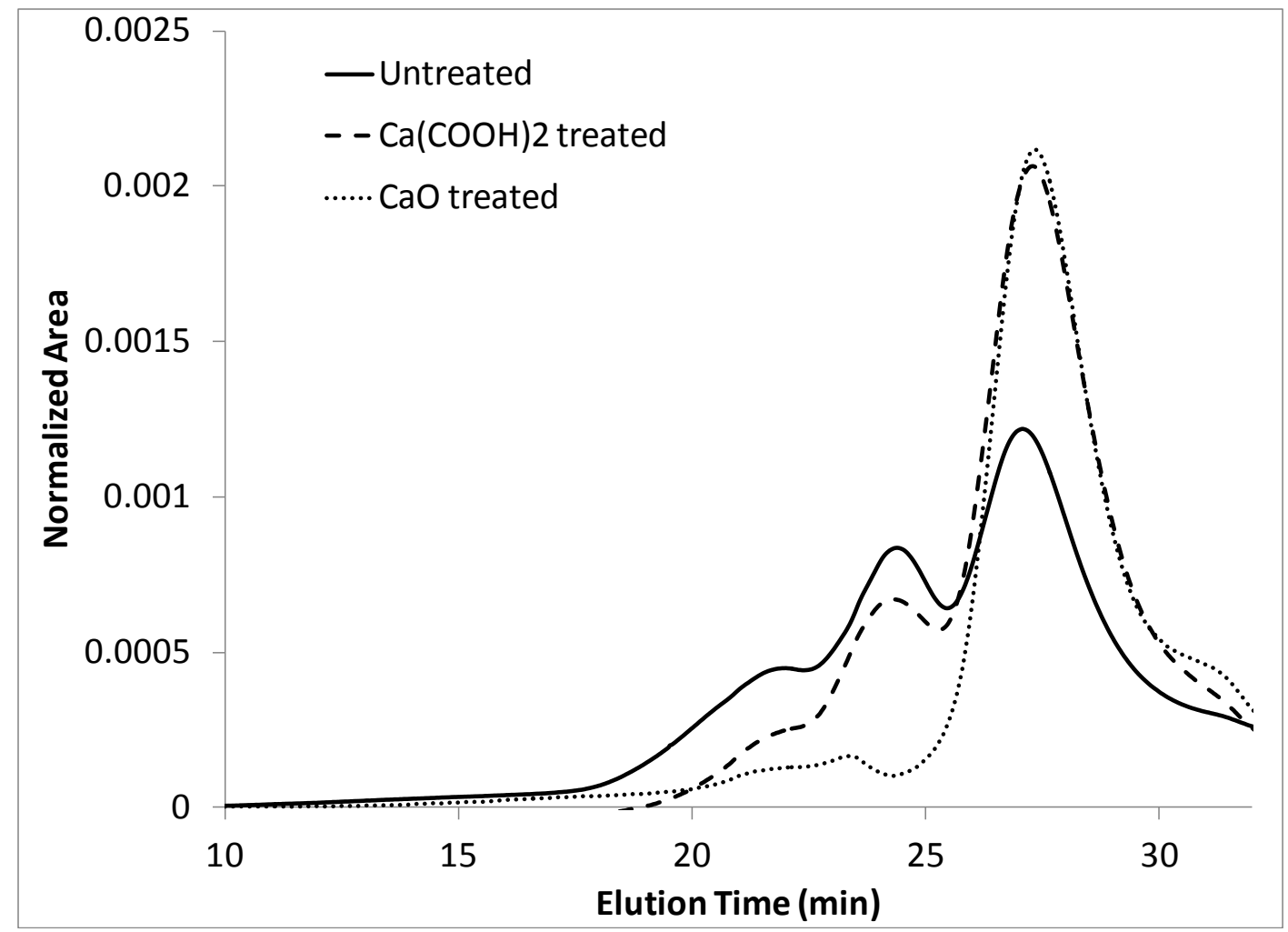

Figure 4

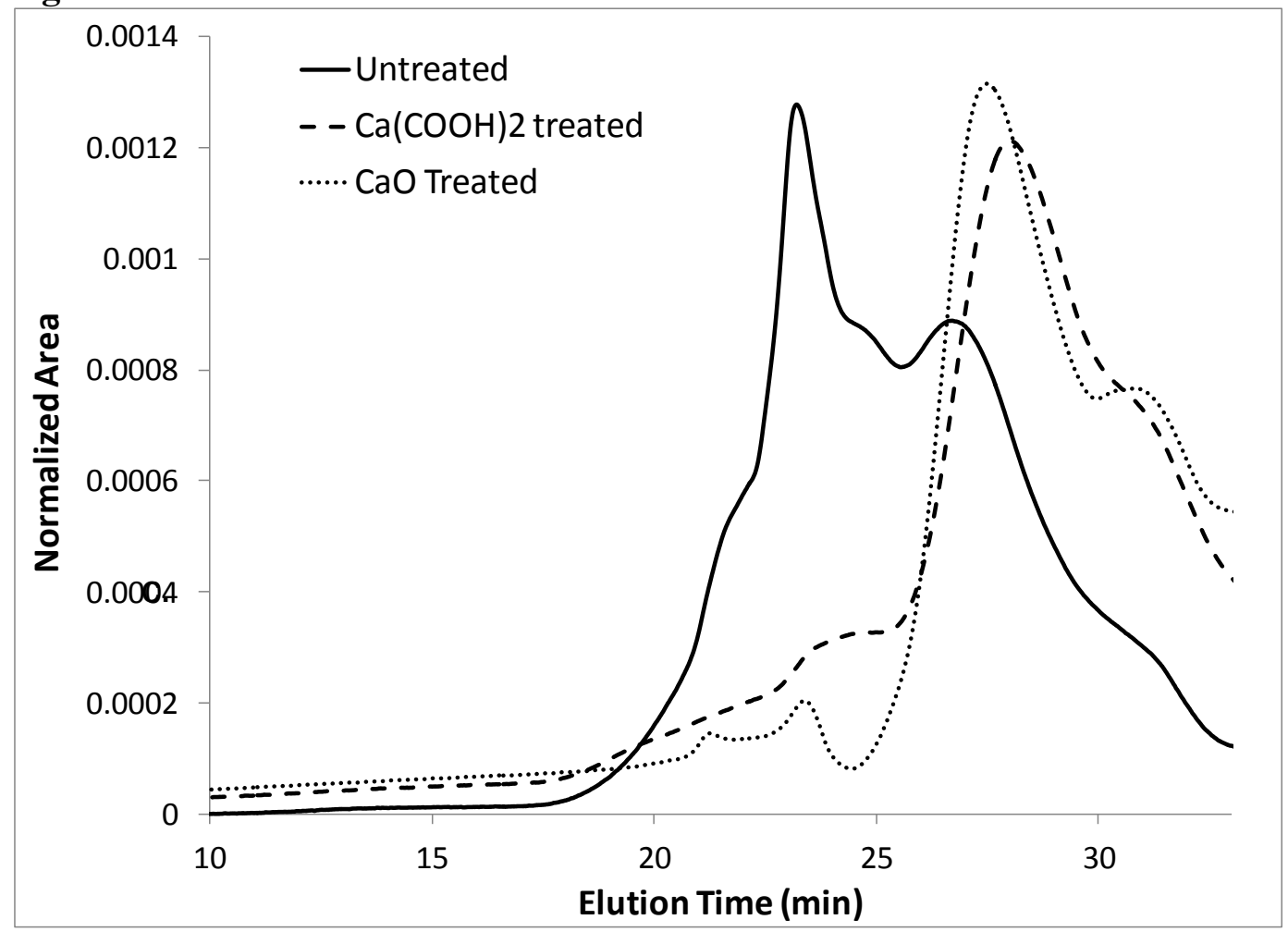


Figure 5.

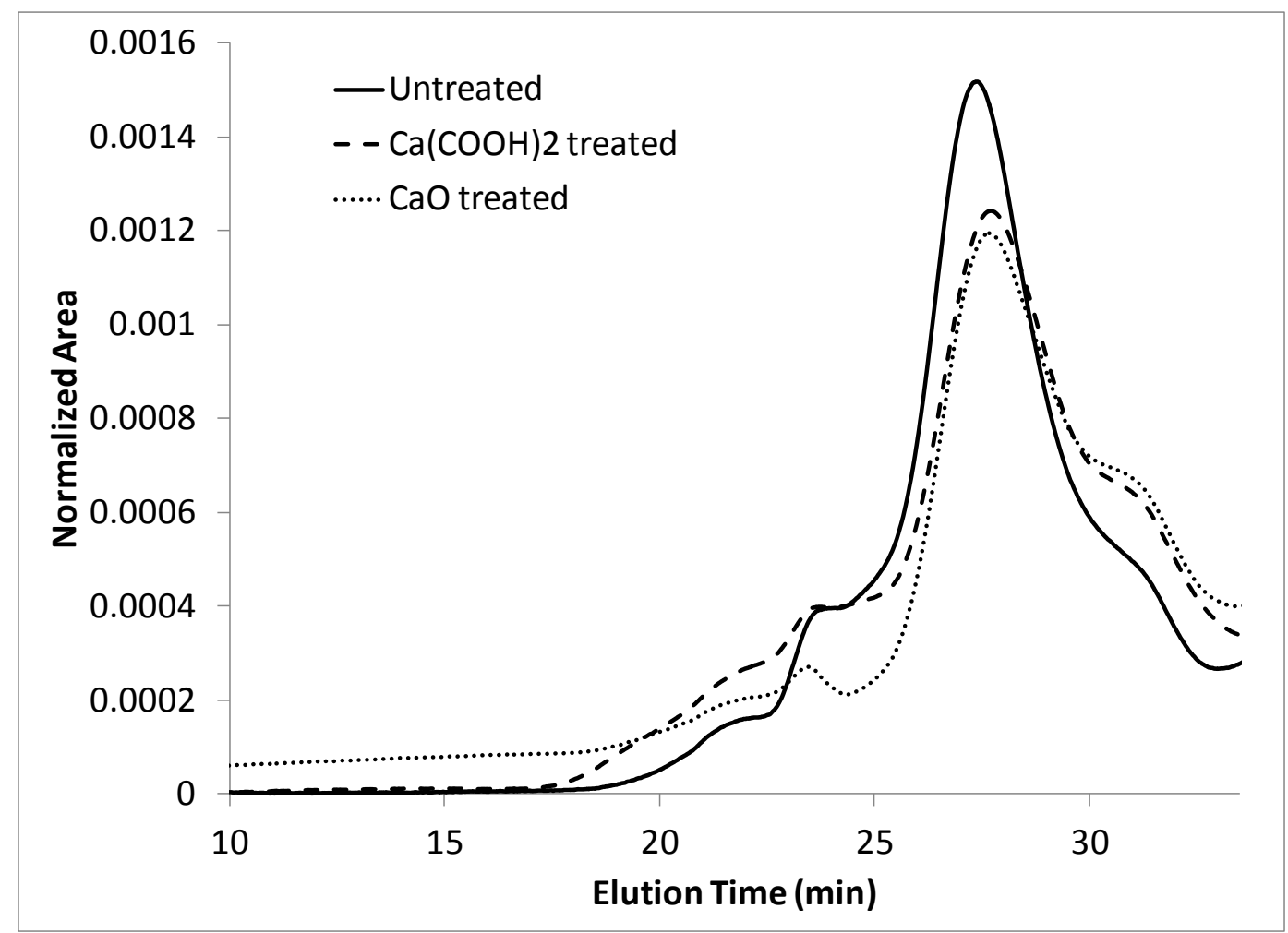

